\title{
A Behavioral Model for Analysis and Intervention of Healthy Dietary Behavior
}

\author{
Jian Wang ${ }^{1}$ \\ ${ }^{1}$ Taiyuan, Shanxi, China \\ Correspondence: Jian Wang, Shanxi 9Grain Agricultural Development Co., Ltd. Economic Crops Research \\ Institute, Shanxi Academy of Agricultural Sciences, Longcheng North Street, Xiaodian District, Taiyuan, Shanxi, \\ China. E-mail: wangjian945@live.com
}

Received: January 19, 2020 Accepted: March 2, 2020 Online Published: March 12, 2020

doi:10.5539/gjhs.v12n4p57 URL: https://doi.org/10.5539/gjhs.v12n4p57

\begin{abstract}
Proper diet is an important way to improve and maintain health, which involves the comprehensive matching of food (category, quantity) and individual (physical fitness, health). Behavior is the key point to achieve this matching. Without behavior change, all cognition and motivations can't get any tangible health benefits. The aim of this study was to construct a model for analysis and intervention of healthy dietary behavior (HDB). Based on the Integrated Behavioral Model (IBM), Maslow's hierarchy of needs and Satter's hierarchy of food needs, this study abstracted the characteristics of longevity, specificity and uncertainty of Healthy Dietary Behavior, constructed a Healthy Dietary Behavioral Model (HDBM), divided 9 negative behaviors of healthy diet (NBHD), and put forward 9 behavior interventions, which could provide ideas for change and habit formation of HDB.
\end{abstract}

Keywords: diet, health, healthy dietary behavior, needs, behavioral model, interventions, health education, reinforcement

\section{Introduction}

Personal behavior influences one's health (Ryan, 2009). As for the improvement of health through dietary behavior, it is a human need since ancient times. Without behavior, all cognition and motivations can't get any tangible health benefits. Therefore, on how to promote health through diet, in addition to pay attention to the dietary pattern which is widely known, it's also essential to make behavior change happen smoothly. However, changing one's health behaviors is a more complex process than originally envisioned (Ryan, 2009). It is a reliable way to make full use of behavioral change theories to study the methods for promoting healthy dietary behavior (HDB). Many behavioral theories involve different fields, such as work motivation, student education, health promotion, etc. But there is no specific theory or model for dietary behavior. From the perspective of health maintenance, dietary behavior belongs to the field of health promotion, but it has its own characteristics. For promoting HDB more effectively, it is necessary to develop a theory or model for dietary behavior.

The aim of this study was to construct a model of dietary behavior through reference and combination of the existing theories related to dietary behavior, so as to provide a tool for the analysis and intervention of HDB, promote people's dietary behavior change, and finally improve their health.

\section{Methods}

\subsection{Selection of Behavioral Change Theories}

A modest number of behavioral theories and models have been used most often to investigate health behaviors (Montaño \& Kasprzyk, 2008), including Social Cognitive Theory, Health Belief Model, theory of subjective culture, and The Transtheoretical Model, Theory of Reasoned Action (TRA), Theory of Planned Behavior (TPB), Integrated Behavioral Model (IBM), and etc.

The first reason IBM was chosen was its comprehensiveness. IBM includes constructs from both TPB and TRA, as well as constructs from other excellent theories of behavior (Montaño \& Kasprzyk, 2008). IBM adopted TRA/TPB's behavioral intention, behavioral beliefs, normative beliefs (others' expectations), control beliefs, increased feelings about behavior, normative beliefs (others' behavior), efficacy beliefs, and adjusted attitude, perceived norm, and personal agency. Four other components directly affect behavior (Montaño \& Kasprzyk, 2008): knowledge and skills to perform the behavior, salience of the behavior, environmental constraints, habit. 
Finally, as noted in the descriptions of TRA and TPB, other demographic, personality, attitudinal, and individual difference variables may be associated with behaviors, but their influence is indirect, through the theoretical constructs. They are considered distal variables (Montaño \& Kasprzyk, 2008).

Second, the most important determinant of behavior in the IBM is intention to perform the behavior. Without motivation, a person is unlikely to carry out a recommended behavior (Montaño \& Kasprzyk, 2008). This is more conducive to the analysis of individual behavior in psychological level.

\subsection{Combination of Human Needs Theories}

Behavior is closely related to human's basic needs (see 3.3.1). Explore the basic needs of individuals is useful for behavior analysis and intervention development. The same is true of dietary behavior. And some human needs theories are helpful for understanding dietary behavior. There are many kinds of needs theories with different emphasis, but diversity and/or dietary relevance was the criteria for theories selection. For example, the theories with good diversity include Maslow's hierarchy of needs (Maslow, 1943), Reiss's 16 basic desires theory (Reiss, 2004), and Satter's hierarchy of food needs (Satter, 2007), and the last one has high dietary relevance. Meanwhile, some theories don't meet these criteria, such as Alderfer's ERG (Existence, Relevance, Growth) theory, Herzberg's two-factor theory, McClelland's achievement motivation theory, and Vroom's expectation theory.

After preliminary selection, some repetitive or irrelevant contents of theories were removed, and then the selected theories were analogized, classified, abstracted and combined, to explore the diverse needs that influence dietary behavior internally.

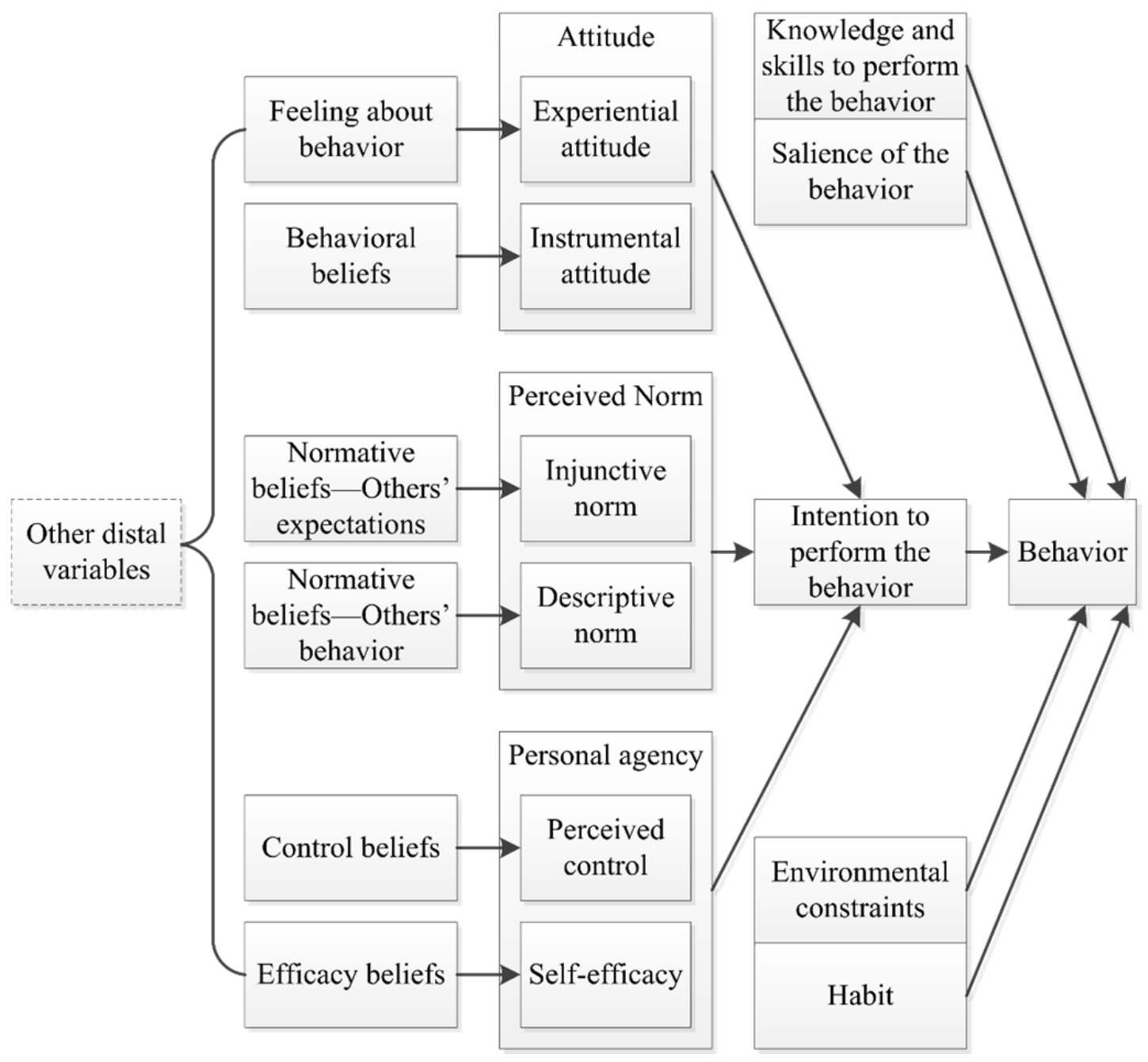

Figure 1. Integrated Behavioral Model (Montaño, \& Kasprzyk, 2008)

\subsection{Hypothesis}

Through the abstraction and classification of the selected dietary needs theory, the characteristics of HDB were 
studied. Then the selected theory of behavioral change and dietary needs were combined to construct a Healthy Dietary Behavioral Model (HDBM). Based on HDBM, some negative behaviors of healthy diet (NBHD) were studied by abstraction and classification, and intervention measures were proposed. The HDBM and its corresponding interventions could be expected to be validated by epidemiological methods, such as observation and experiment.

\section{Results}

\subsection{Application of IBM to Dietary Behavior}

IBM (Figure 1) can be applied to the analysis and intervention of diverse behaviors, as well as the dietary behavior.

Took some dietary behaviors as examples and made hypotheses of IBM components, as in Table 1.

Table 1. IBM Components Hypothesis for Dietary Behavior

\begin{tabular}{|c|c|}
\hline Components & Components Hypothesis \\
\hline Intention to perform the behavior & I tend to adopt the balanced diet. \\
\hline Attitude & $\begin{array}{l}\text { The overall favorableness or unfavorableness toward performing the balanced diet } \\
\text { based on affective and cognitive dimensions. }\end{array}$ \\
\hline Experiential attitude & I like a balanced diet. \\
\hline \multirow[t]{2}{*}{ Feelings about behavior } & $\begin{array}{l}\text { Eating a delicious meal at home is one of the main sources of happiness in life } \\
\text { (Chinese Nutrition Society [CNS], 2016). }\end{array}$ \\
\hline & $\begin{array}{l}\text { Colorful fruits and vegetables not only decorate the table, but also delight our mood } \\
\text { (CNS, 2016). }\end{array}$ \\
\hline Instrumental attitude & $\begin{array}{l}\text { The balanced diet can meet the needs of normal growth and development of the } \\
\text { human body and various physiological activities to the greatest extent (CNS, 2016). }\end{array}$ \\
\hline \multirow[t]{4}{*}{ Behavioral belief } & I believe in the following: \\
\hline & $\begin{array}{l}\text { The lower your salt intake is, the lower your blood pressure (National Heart, Lung, } \\
\text { and Blood Institute [NHLBI], 2006). }\end{array}$ \\
\hline & $\begin{array}{l}\text { (Regular intake of) whole grains reduces the risk of diabetes, obesity, cardiovascular } \\
\text { disease and colon cancer (CNS, 2016). }\end{array}$ \\
\hline & Increasing the intake of potato can improve constipation (CNS, 2016). \\
\hline \multirow[t]{2}{*}{ Evaluation } & $\begin{array}{l}\text { I think it's very plausible that whole grains can reduce the risk of diabetes, obesity, } \\
\text { cardiovascular disease and colon cancer. }\end{array}$ \\
\hline & $\begin{array}{l}\text { I think it's very believable that increasing the intake of potatoes can improve } \\
\text { constipation. }\end{array}$ \\
\hline Perceived Norm & Based on the perceived norm, I tend to follow the balanced diet. \\
\hline Injunctive norm & Most people encourage me to follow the balanced diet. \\
\hline Normative beliefs & My family encourages me to follow the balanced diet. \\
\hline (Others' expectations) & Many friends encourage me to follow the balanced diet. \\
\hline \multirow[t]{2}{*}{ Motivation to comply } & I am very willing to follow the advice of my family. \\
\hline & I'm willing to follow the advice of my friends. \\
\hline Descriptive norm & Most people follow the balanced diet. \\
\hline Normative beliefs & My family follows the balanced diet. \\
\hline (Others' behavior) & Many friends follow the balanced diet. \\
\hline Personal Agency & $\begin{array}{l}\text { After a comprehensive assessment of my own capabilities and environmental factors } \\
\text { (favorable and unfavorable), I feel a strong sense of personal agency. }\end{array}$ \\
\hline Perceived control & $\begin{array}{l}\text { After a comprehensive assessment of environmental factors (favorable and } \\
\text { unfavorable), I think they have not much effect on behavior control. }\end{array}$ \\
\hline Control beliefs & Except that some areas in China belong to the area with high environmental iodine, \\
\hline
\end{tabular}


the environmental iodine content in most areas is relatively low (CNS, 2016).

In order to prevent the harm of iodine deficiency to health, the measure of Iodizing table salt was carried out in China from 1990s (CNS, 2016).

Lack of dairy products in underdeveloped areas.

Perceived power

The low iodine content in the area has a great impact on the iodine intake.

Iodizing table salt is very beneficial to iodine intake.

The lack of dairy products in underdeveloped areas of transportation has a certain impact on the intake of dairy products.

\begin{tabular}{ll}
\hline Self-efficacy & I am very sure that I have the ability and the means to follow the balanced diet. \\
\hline Efficacy beliefs & $\begin{array}{l}\text { I'm pretty sure I'll stick to intake iodized salt. } \\
\text { If the traffic is inconvenient, I'm not sure I can keep on eating dairy products. }\end{array}$ \\
\hline $\begin{array}{l}\text { Knowledge and skills to perform the } \\
\text { behavior }\end{array}$ & (I know how to) design a balanced diet and manage three meals a day (CNS, 2016). \\
& I know how to reduce the salt and sodium content in my diet. \\
\hline Salience of the behavior & $\begin{array}{l}\text { People with confirmed milk protein allergy should avoid drinking milk (CNS, 2016). } \\
\text { If you are allergic to nuts, use seeds or legumes (cooked dried beans or peas) (NHLBI, } \\
\text { 2006). }\end{array}$ \\
\hline Environmental constraints & $\begin{array}{l}\text { People who eat outside to eat more drinks, sugar, desserts and bread than those who } \\
\text { eat at home (CNS, 2016). }\end{array}$ \\
\hline Habit & Vegetarian diet is a kind of eating habit or culture (CNS, 2016). \\
& I have the habit of eating snacks while watching TV. \\
\hline
\end{tabular}

\subsection{Characteristics of Dietary Behavior}

\subsubsection{Diversity of Dietary Needs}

People's needs are diverse (Peng, 2001), which is also reflected in the dietary needs. Based on Maslow's hierarchy of needs and Satter's hierarchy of food needs, this study proposed a theory of diversity of dietary needs (DDN, hereinafter also referred to as diversity), as in Table 2.

Table 2. Diversity of Dietary Needs

\begin{tabular}{|c|c|}
\hline Dietary Needs & Description \\
\hline Enough & The need for food to meet hunger. \\
\hline \multirow[t]{2}{*}{ Safety } & The need for food safety and hygiene. \\
\hline & $\begin{array}{l}\text { Food should not contain all kinds of harmful factors that may cause harm to the human body, and fresh and } \\
\text { hygienic food should be kept to ensure the life safety of residents (Liu, 2017). }\end{array}$ \\
\hline Tasty & The need for food sensory, such as color, aroma and taste. \\
\hline \multirow[t]{2}{*}{ Novelty } & The need for food or dietary behavior in terms of novelty. \\
\hline & It's kind of human desires to know and to understand. \\
\hline Function & $\begin{array}{l}\text { The need for food or dietary behavior in terms of function, such as health (physiology, psychology), } \\
\text { athletic performance. }\end{array}$ \\
\hline \multirow[t]{2}{*}{ Emotion } & The need for food or dietary behavior in terms of emotion. \\
\hline & For example, chocolate can convey love, while Thanksgiving turkey can express gratitude. \\
\hline \multirow[t]{2}{*}{ Esteem } & The need for food or dietary behavior to gain self-esteem or respect from others. \\
\hline & Take dining etiquette as an example, people express or seek respect through specific dietary behaviors. \\
\hline Self-actualization & $\begin{array}{l}\text { The need for food or dietary behavior to realize (such as) personal potential, self- Some people take the } \\
\text { study of recipes or cooking skills as a lifelong pursuit, and get the satisfaction of life. }\end{array}$ \\
\hline
\end{tabular}
Note.

(1) Diversity: It refers to that the dietary needs vary according to the differences of personal's physiological state, psychology 
sate, and circumstance. The diverse needs can exist at the same time.

(2) Volatility: Human needs are regulated and controlled by consciousness (Peng, 2001), and consciousness is affected by physiological and psychological state (as well as the related cognition and circumstance, etc.), so the human needs fluctuates (increase or decrease) with time and circumstance, and then affects motivation and behavior. Volatility is a dynamic response of diversity. For example, people who refuse to drink because of their health needs are likely to drink when their emotion needs temporarily increase at a party.

(3) Health needs: the HDB mentioned in this study is based on health needs, which is an important part of function needs.

\subsubsection{Longevity of HDB}

HDB cannot change the health status overnight, which is related to the natural properties of food and the physiological regulatory mechanisms, so it is necessary to implement the behavior continuously. Without longevity of HDB, it is difficult to maintain health, or even go back to an unhealthy condition. Just like yo-yo effect, although they are initially successful in producing weight loss, such lifestyle intervention strategies are generally unsuccessful in achieving long-term weight maintenance, with the vast majority of obese patients regaining their lost weight during follow up. Recently, various compensatory mechanisms have been elucidated by which the body may oppose new weight loss, and this compensation may result in weight regain back to the obese baseline (Blomain, Dirhan, Valentino, Kim, \& Waldman, 2013).

\subsubsection{Specificity of Dietary Behavior Methods}

Behavior methods are not the behavior, but the particular ways of implementing the behavior to meet the needs. Behavior methods are abstracted from the behavior and can guide the behavior. When taking the population as the research object, some common dietary behavior methods gradually form typical dietary patterns, such as Mediterranean diet, DASH (Dietary Approaches to Stop Hypertension), Atkins diet, TLC (Therapeutic Lifestyle Changes), etc. The effects of these patterns on health are claimed with different emphasis, for example, DASH to stop hypertension, Atkins to lose weight, TLC to cut cholesterol, this is the specificity of dietary behavior methods (hereinafter referred to as specificity).

\subsubsection{Effect Uncertainty of HDB}

From the perspective of individual differences, the health effects, such as degree and implementation time, brought by even the same food and dietary behavior vary with person and time, that is the effect uncertainty of HDB (hereinafter referred to as uncertainty), which is related to the physical fitness and health status of individuals. This has been confirmed by a study, which found (different people have) high variability in the response to identical meals, suggesting that universal dietary recommendations may have limited utility (Zeevi et al., 2015). This means that people should look closely at the matching between themselves and food/diet, and look for the proper dietary patterns. 


\subsection{Healthy Dietary Behavioral Model}

To facilitate the analysis of HDB, IBM and DDN were combined to form a Healthy Dietary Behavioral Model (HDBM, Figure 2).

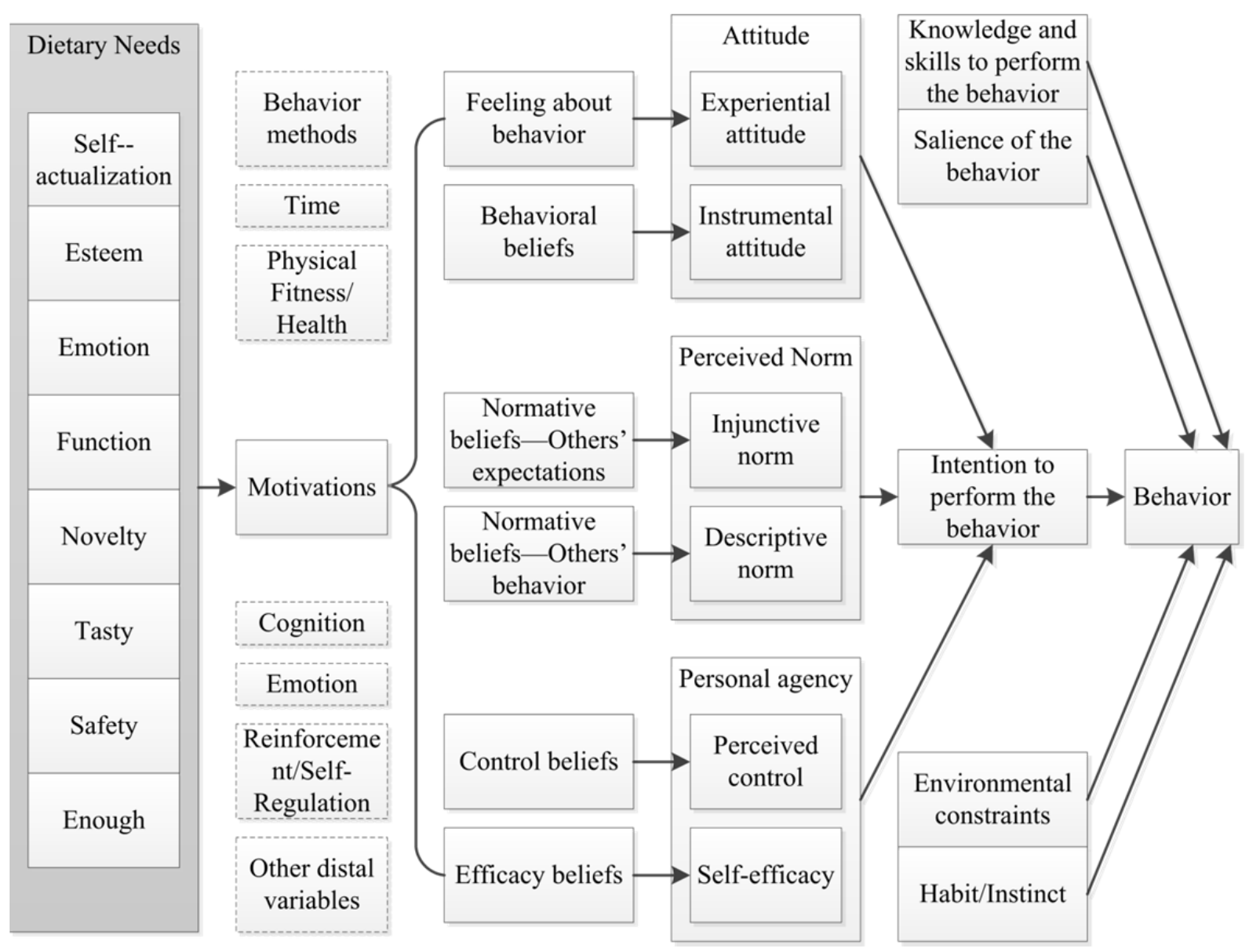

Figure 2. Healthy Dietary Behavioral Model

\subsubsection{Dietary Needs}

Need is a kind of imbalance state in the organism, which is manifested in a stable requirement of the organism for the internal environment or external living conditions (Peng, 2001). Motivation is generated on the basis of need. When a certain need is not met, it will promote people to find the objects to meet the need, thus generating the motivation of activities (Peng, 2001), driving the implementation of behavior, and restoring the balance within the organism to meet the need. Motivation is a kind of internal psychological process or internal driving force, which is the basis of most human behavior (Peng, 2001).

Therefore, behavior is driven by motivation, and motivation comes from the need. In view of the impact of diversity on dietary behavior, HDBM contains the dietary needs, as shown in the shaded boxes in Figure 2.

\subsubsection{Behavior Methods}

HDBM not only focuses on whether the behavior occurs, but also on the effects or the stage effects achieved by the behavior, because the behavior with no or few effects is difficult to continue, and without continuous behavior, the health needs are hard to meet. Behavior methods play an important role in behavioral effects.

Behavior methods are not immutable. The longevity, specificity and uncertainty determine that behavior methods should be adjusted in time to match people's cognitive, physical fitness/health, needs, knowledge and skills, so as to achieve effects or stage effects, and promote the continuous behavior. Behavior methods can be adjusted by the mechanisms of reinforcement and self-regulation (see 3.3.8). 


\subsubsection{Habit/Instinct}

In IBM, habit directly affects behavior. Instinct is our natural reaction, it occurs without learning or even thinking, and it can also directly affect behavior (such as chewing and swallowing). Therefore, the instinct was added in HDBM.

\subsubsection{Time}

The acquisition or change of behavior usually requires constant reinforcement. The reinforcement which develops skill must be immediate. Otherwise, the precision of the differential effect is lost (Skinner, 2014), and the behavior is hard to change. Therefore, the time interval between behavior and reinforcement is very important for behavior change.

\subsubsection{Physical Fitness/Health}

Physical fitness refers to the special state of relatively stable structure, function and metabolism, formed by groups and individuals in the process of growth, development and aging under the influence of heredity and environment, which determines the specificity of physiological response, the susceptibility of organism to certain pathogenic factors and the tendency of pathological changes (Jiang, \& Zhang, 2008). Health is a dynamic and satisfying state of physiology, psychology, spirituality and society, not just the absence of disease and weakness (Lv, 2017). Health is unstable and changeable.

Physical fitness and health are the biological basis affecting human behavior, which widely affect needs, motivation, behavior methods, attitude, perceived norm, personal agency, habit/instinct, knowledge and skills, and salience of the behavior, etc.

\subsubsection{Cognition}

Belief and its evaluation belong to cognition category, while attitude, perceived norm and personal agency are all based on belief and/or evaluation, so cognition affects these three components in the HDBM.

The knowledge and skills to perform the behavior in HDBM are also affected by cognition.

The needs, motivation, and behavior methods in HDBM also based on cognition, such as the cognition of one's own physical fitness/health, health needs, and function of dietary patterns or foods.

Therefore, cognition has a wide influence on many components in HDBM.

\subsubsection{Emotion}

Emotion is a kind of inner feeling or attitude of human beings towards various cognitive objects (Liao, 2012). Emotions affect the way that we think and behave in a variety of personal and social contexts (Haselton \& Ketelaar, 2006). In Albert Bandura's social cognitive theory of learning, emotion also affects self-efficacy. Moreover, Human needs are the important basis of emotion generation (Liao, 2012). And emotion is also one of the sources of motivation (Peng, 2001).

It is widely accepted that the eating behavior in humans, changes according to changes in their emotional arousal (anxiety, anger, joy, depression, sadness and other emotions) (Canetti, Bachar, \& Berry, 2002). This relationship varies according to the particular characteristics of the individual and according to the specific emotional state (Canetti, Bachar, \& Berry, 2002).

In a word, emotion should not be ignored in HDBM.

\subsubsection{Reinforcement/Self-Regulation}

According to B. F. Skinner, reinforcement is a term in operant conditioning theory and behavior analysis for process of increasing the rate or probability of behavior, in the form of response delivered shortly after performing the behavior (Kinyanjui, Aloka, Mutisya, Ndeke, \& Nyang'ara, 2015). According to Albert Bandura, reinforcement includes not only direct reinforcement, but also vicarious reinforcement and self-reinforcement, and he proposed the concept of self-regulation. People possess self-reflective and self-reactive capabilities that enable them to exercise some control over their thoughts, feelings, motivation, and actions (Bandura, 1991), which provides the possibility of self-regulation. In fact, they not only mediate the effects of most external influences, but provide the very basis for purposeful action (Bandura, 1991).

The improvement and maintenance of health need longevity of HDB, and reinforcement is an important method, such as self-reinforcement (or self-regulation) after own health improvement, direct reinforcement after doctor's approval, vicarious reinforcement caused by knowing others' health improvement. After people attain the standard they have been pursuing, those who have a strong sense of efficacy generally set a higher standard for themselves 
(Bandura, 1991), and guide their behavior to a higher standard, which is another function of self-reinforcement (or self-regulation). Therefore, reinforcement and self-regulation are the key mechanisms for the dynamic operation of HDBM. And the basic reason is, they affect many components of HDBM, such as motivation (needs), behavior, attitude, perceived norms, personal agency, cognition, emotion, knowledge and skills.

\subsubsection{Others}

The attitude, perceived norm, personal agency, and other distal variables are also available in HDBM.

\section{Discussion}

\subsection{Negative Behaviors of Healthy Diet}

If any one or more components of HDBM do not produce enough positive effects, or even negative effects, they may cause negative behaviors of healthy diet (NBHD), as in Table 3.

Table 3. 9 Basic Types of NBHD

\begin{tabular}{|c|c|c|c|}
\hline Types & $\begin{array}{l}\text { Function } \\
\text { Components }\end{array}$ & Reasons & Examples \\
\hline No-needs & Needs/Motivation & Low health needs or motivation. & $\begin{array}{l}\text { I have no need to change my } \\
\text { diet. }\end{array}$ \\
\hline Volatility & Needs & The volatility of needs leads to behavior deviation. & I drink to respect the party host. \\
\hline Ignorance & Behavior Methods & Don't know how to behave. & $\begin{array}{l}\text { I don't know what kind of } \\
\text { dietary patterns I should adopt. }\end{array}$ \\
\hline Doubtfulness & Attitude & $\begin{array}{l}\text { Lack of positive emotion or evaluation of behavior } \\
\text { and results. }\end{array}$ & $\begin{array}{l}\text { I think this dietary pattern has } \\
\text { little benefit. }\end{array}$ \\
\hline Blind & Perceived Norm & $\begin{array}{l}\text { Lack of judgment, blindly imitate the behavior of } \\
\text { others or follow others' suggestions. }\end{array}$ & $\begin{array}{l}\text { All my friends drink, so I should } \\
\text { drink too. }\end{array}$ \\
\hline \multirow[b]{2}{*}{ Incapability } & Personal Agency & $\begin{array}{l}\text { Think that the ability is incompetent or there are } \\
\text { many adverse factors that cannot change behavior. }\end{array}$ & $\begin{array}{l}\text { It's hard for me to resist the } \\
\text { temptation of sweets. }\end{array}$ \\
\hline & $\begin{array}{l}\text { Knowledge and } \\
\text { Skills }\end{array}$ & Lack of some necessary skills. & $\begin{array}{l}\text { I don't know how to estimate } \\
\text { the portion of food and calculate } \\
\text { the energy. }\end{array}$ \\
\hline Habit/instinct & Habit/instinct & $\begin{array}{l}\text { Behavior change needs conscious participation, } \\
\text { and once attention drops, the original habits or } \\
\text { instinct are easy to occur. }\end{array}$ & Habitual Drinking \\
\hline \multirow{2}{*}{ Constraint } & $\begin{array}{l}\text { Salience of the } \\
\text { behavior }\end{array}$ & Forced by salience of the behavior. & $\begin{array}{l}\text { It's very important for me to } \\
\text { have a cake for my birthday. }\end{array}$ \\
\hline & $\begin{array}{l}\text { Environmental } \\
\text { constraints }\end{array}$ & Forced by environmental constraints & $\begin{array}{l}\text { There is no milk supply in this } \\
\text { area. }\end{array}$ \\
\hline Emotion & Emotion & Emotion influences eating behavior. & $\begin{array}{l}\text { Emotional Eating } \\
\text { (Through eating to suppress or } \\
\text { alleviate negative emotions) }\end{array}$ \\
\hline
\end{tabular}

Generally, people's difficulties in changing HDB may result from one or more of the NBHD.

\subsection{Intervention of $H D B$}

\subsubsection{Health Education}

Some NBHDs are affected by the lack of cognition and skills, such as the no-needs type is lack of understanding of their own health status; the ignorance type is lack of understanding of dietary patterns; the doubtfulness type may lack of understanding of the effect of dietary behavior; the blind type is partly due to the lack of judgment on other people's behavior; the incapability type is partly due to a lack of certain skills; the constraint type is partly due to the understanding deviation of the salience of the behavior; the emotion type may lack the correct understanding of 
the emotional behavior and the ability to relieve emotion. The deficiency of the cognition and skills is a manifestation of low health literacy, and health education is an effective means to improve health literacy (Yu, 2013).

Health education is a planned, organized and systematic social education activity to promote people to consciously adopt behaviors and lifestyles that are beneficial to health (Yu, 2013). How to adopt a proper dietary pattern is also an important part of health education. Therefore, through health education, make people pay attention to their own physical fitness and health status, activate their needs and motivation, understand the health knowledge, improve their judgment of dietary behavior, learn necessary skills, correct (if necessary) the salience of the behavior, so as to cultivate healthy lifestyle and behavior. Reflected in HDBM, health education should be adopted to influences components such as needs, motivation, attitude, motivation to comply, personal agency, skills and knowledge, salience of the behavior, emotion, and so on, and then promotes people to change their behavior actively.

\subsubsection{Environment Identification}

Environment can directly affect behavior, such as constraint type caused by environmental constraints; it can indirectly affect behavior through influencing other components, such as the volatility type caused by affecting needs, the incapability type caused by reducing control belief; it can also trigger habit/instinct type through inducing habit/instinct; and provide convenience for behavior to boost emotion type.

The environment contains various clues, which induce the change of behavior. Therefore, identifying and changing this environment is a way to avoid unhealthy dietary behaviors. For example, if you do not want to drink, you should try to stay away from the occasion of drinking and avoid constraint type.

On the habitual behavior induced by the environment, according to Charles Duhigg, there is a loop that includes a cue, routine and reward for every habit. An example of a habit loop is TV program ends (cue), go to the fridge (routine), eat a snack (reward). The key to changing habits is to identify your cue and modify your routine and reward (Wikipedia, 2017). In this example, the TV programs and snacks stored in the refrigerator are all parts of the environment. Identifying and adjusting these elements can effectively block the habit of snack intake, such as not storing snacks in the refrigerator. This way of avoiding food being too easy to obtain is also suitable for emotion type, provided that the environmental elements are identified.

\subsubsection{Needs Activation}

The longevity, uncertainty of HDB, and the deviation of behavior methods are easy to cause the lack of personal motivation and negative attitude, resulting in incapability and doubtfulness type, which is not conducive to the continuous occurrence of behavior, but the same behavior can be driven from different needs (motivation), which means that some needs (motivation) other than health can also drive HDB. For example, if someone insists on HDB for one week, he will be given an external reward as a reinforcement to activate and meet his respect needs. Compared with the change of health status, this goal can be achieved in a short time, the behavior method is clear, the effect is predictable, and it is easier to reinforce the recurrence of behavior.

The no-needs type lacks the needs and motivation to drive behavior, while the volatility type causes behavior deviation due to needs volatility. These two types can also set new stable needs (or multiple needs and motivations) through needs activation, clarify the behavior methods and expected effect, and then drive new behavior intention, reinforce in time, guide self-regulation, and promote the continuing occurrence of HDB.

\section{(1) Goal Decomposition}

According to B. F. Skinner, the whole process of becoming competent in any field must be divided into a very large number of very small steps, and reinforcement must be contingent upon the accomplishment of each step. This solution to the problem of creating a complex repertoire of behavior also solves the problem of maintaining the behavior in strength (Skinner, 2016). HDB is a collection of a series of behaviors, through goal decomposition, it is conducive to change behavior and an effective way to deal with ignorance type. At the same time, when setting new behavior goals through needs activation, actively reinforce each small goal in time, which is not only conducive to goal realization, but also can enhance self-efficacy through continuous reinforcement, which is an effective way to deal with incapability type. If the goal decomposition is not suitable for one's own situation, for example, beyond one's ability, it will lead to the reduction of self-efficacy, and is not conducive to behavior change.

(2) Immediate Reinforcement

According to B. F. Skinner, the reinforcement which develops skill must be immediate. Otherwise, the precision of the differential effect is lost (Skinner, 2014), and then it is difficult to change behavior, which is one of the reasons 
why many people give up on changing dietary behavior. The reinforcement refers in particular to direct reinforcement. For HDB, we should not only use needs activation and goal decomposition, but also immediate reinforcement. Immediate reinforcement is mainly aimed at incapability type.

\section{(3) Diversity Reinforcement}

People's needs are diverse, and different people have different needs. Therefore, the ways of reinforcement should vary with each individual to ensure a good reinforcement effect.

Human needs has volatility. Although reinforcement promotes behavior, the effect of continuous reinforcement tends to decrease. This phenomenon stems from the decrease of people's perception of external stimulus, which is called marginal utility in psychology. Therefore, the reinforcement should be varied in the way and degree according to people's current needs, and then avoid the decrease of reinforcement effect.

Diversity reinforcement is mainly aimed at incapability type.

\subsubsection{Circle Learning}

The sum of people and things that people contact in daily life is defined as a circle which is an important source of people's observing and learning objects.

For unhealthy or unsuitable dietary behaviors, if people lack of judgment, it is easy to produce blind type. In order to avoid this negative behavior, in addition to health education, a suitable source of learning objects, which is a circle, should be chosen. For example, people tend to adopt the DASH when most of friends adopt that, because the circle affect the perceived norms.

In addition to directly influencing perceived norms, circles also indirectly affect needs (motivation), cognition, cognitive related components (attitude and personal agency, etc.), and self-regulation mechanism through social referential comparisons (Bandura, 1991), indirectly having the function of needs activation and health education.

\subsubsection{Emotion Attention}

Some emotions are easy to lead to unhealthy dietary behaviors, such as emotional eating, which shows improper changes in needs (motivation) and behavior methods in HDBM.

Behavior intervention should focus on and adjust emotions, such as stress management, relaxing with friends, avoiding boredom, etc., integrate section 4.2.2 (environmental identification), and change environmental factors, such as removing food. If you've tried self-help options but you still can't control emotional eating, consider therapy with a mental health professional. Therapy can help you understand why you eat emotionally and learn coping skills (Mayo Clinic, 2019). To a certain extent, it belongs to 4.2.1 health education.

\subsubsection{Persistent Intervention}

The longevity of HDB determines the persistent behavior intervention whose purpose is to make people develop and maintain HDB habits and avoid the recurrence of unhealthy behavior.

\subsubsection{The Interventions for NBHD}

Different interventions can affect one or more NBHD directly or indirectly. Table 4 shows the interventions that can affect NBHD directly.

Table 4. Interventions that Affect NBHD Directly

\begin{tabular}{|c|c|c|c|c|c|}
\hline Interventions & No-needs & Volatility & Ignorance & Doubtfulness & Blind \\
\hline Health Education & $\sqrt{ }$ & $\sqrt{ }$ & $\sqrt{ }$ & $\sqrt{ }$ & $\sqrt{ }$ \\
\hline Environment Identification & $x$ & $\sqrt{ }$ & $x$ & $x$ & $x$ \\
\hline Needs Activation & $\sqrt{ }$ & $\sqrt{ }$ & $x$ & $\sqrt{ }$ & $x$ \\
\hline Goal Decomposition & $x$ & $x$ & $\sqrt{ }$ & $x$ & $\times$ \\
\hline Immediate Reinforcement & $\times$ & $x$ & $x$ & $x$ & $x$ \\
\hline Diversity Reinforcement & $x$ & $x$ & $x$ & $x$ & $x$ \\
\hline Circle Learning & $x$ & $x$ & $x$ & $x$ & $\sqrt{ }$ \\
\hline Emotion Attention & $x$ & $x$ & $x$ & $x$ & $x$ \\
\hline
\end{tabular}




\begin{tabular}{lllll}
\hline Interventions & Incapability & Habit/instinct & Constraint & Emotion \\
\hline Health Education & $\sqrt{ }$ & $\times$ & $\sqrt{ }$ & $\sqrt{ }$ \\
\hline Environment Identification & $\sqrt{ }$ & $\times$ & $\sqrt{ }$ & $\times$ \\
\hline Needs Activation & $\sqrt{ }$ & $\times$ & $\times$ & $\times$ \\
\hline Goal Decomposition & $\sqrt{ }$ & $\times$ & $\times$ & $\times$ \\
\hline Immediate Reinforcement & $\sqrt{ }$ & $\times$ & $\times$ & $\times$ \\
\hline Diversity Reinforcement & $\sqrt{ }$ & $\times$ & $\times$ & $\sqrt{ }$ \\
\hline Circle Learning & $\times$ & $\times$ & & $\times$ \\
\hline Emotion Attention & $\times$ & & $\times$
\end{tabular}

(1) Goal decomposition, immediate reinforcement and diversity reinforcement are usually used on the premise of needs activation, so the unified shadow display is adopted. Besides, goal decomposition can also be used alone.

(2) $" \sqrt{ } "$ means it can affect directly, but " $\times$ " means it can't.

\section{Conclusion}

This study constructed HDBM, which can provide a tool for the analysis and intervention of HDB. For different negative behaviors, it is necessary to locate the function components, design specific and comprehensive interventions, utilize needs activation, goal decomposition, immediate reinforcement and diversity reinforcement innovatively, attaches great importance to health education, environment identification, circle learning and emotion attention, implement persistent intervention, promote behavior change, form HDB habits, meet health needs, maintain healthy state.

\section{Competing Interests Statement}

The author declares that there are no competing or potential conflicts of interest.

\section{References}

Bandura, A. (1991). Social cognitive theory of self-regulation. Organizational Behavior and Human Decision Processes, 50(2), 248-287. https://doi.org/10.1016/0749-5978(91)90022-L

Blomain, E. S., Dirhan, D. A., Valentino, M. A., Kim, G. W., \&Waldman, S. A. (2013). Mechanisms of weight regain following weight loss. ISRN Obesity, 2013, 210524. https://doi.org/10.1155/2013/210524

Canetti, L., Bachar, E., \& Berry, E. M. (2002). Food and emotion. Behavioural Processes, 60(2), 157-164. https://doi.org/10.1016/S0376-6357(02)00082-7

Chinese Nutrition Society. (2016). The Chinese dietary guidelines (2016). Beijing: People's Medical Publishing House.

Gui, L. H., \& Gao, J. L. (2013). Health literacy. In J. M. Yu (Eds.), Health behavior and health education. Shanghai: Fudan University Press. [In Chinese]

Guo, D. J. (2001a). Emotion and feeling. In D. L. Peng (Eds.), General psychology (Revised Edition) (pp. 354388). Beijing: Beijing Normal University Press.

Guo, D. J. (2001b). Motivation. In D. L. Peng (Eds.), General psychology (Revised Edition) (pp. 319- 353). Beijing: Beijing Normal University Press.

Habit. (2017). In Wikipedia, the free encyclopedia. Retrieved June 28, 2019, from https://en.wikipedia.org/wiki/Habit_(psychology)

Haselton, M. G., \& Ketelaar, T. (2006). Irrational emotions or emotional wisdom? The evolutionary psychology of emotions and behavior. In J. P. Forgas (Ed.), Hearts and minds: Affective influences on social cognition and behavior (pp. 21-40). New York, NY: Psychology Press.

Hou, X. H. (2012). Emotion. In B. Liao (Eds.), Common psychology (pp. 190-208). Beijing: Aviation industry press. [In Chinese]

Jiang, C. M., \& Zhang, Y. M. (2008). The advancement and developing trend of physical fitness study in China. 
China Sport Science, 28(9), 25-32. http://dx.chinadoi.cn/10.3969/j.issn.1000-677X.2008.09.010 [In Chinese]

Kinyanjui, M. W., Aloka, P. J. O., Mutisya, S. K., Ndeke, F. N., \& Nyang'ara, N. M. (2015). Classroom instruction reinforcement strategies and factors that influence their implementation in Kenyan primary Schools. Journal of Educational and Social Research, 5(3), 267. https://doi.org/10.5901/jesr.2015.v5n3p267

Liu, Y. (2017). Fundamentals of nutrition. In C. H. Sun, W. H. Ling, \& G. W. Huang (Eds.), Nutrition and food hygiene (7th ed.) (pp. 16-134). Beijing: People's Medical Publishing House. [In Chinese]

Lv, J. (2017). Strategy for prevention. In S. Y. Zhan, D. Q. Ye, \& H. Z. Tan (Eds.), Epidemiology (7th ed.) (pp. 176-188). Beijing: People's Medical Publishing House. [In Chinese]

Maslow, A. H. (1943). A theory of human motivation. Psychological Review, 50(4), 370-396. https://doi.org/10.1037/h0054346

Mayo Clinic. (2019). Weight loss: Gain control of emotional eating. Retrieved June 28, 2019, from https://www.mayoclinic.org/healthy-lifestyle/weight-loss/in-depth/weight-loss/art-20047342

Montaño, D. E., \& Kasprzyk, D. (2008). Theory of reasoned action, theory of planned behavior, and the Integrated Behavioral Model. In K. Glanz, B. K. Rimer, \& K. Viswanath (Eds.), Health behavior and health education: Theory, research, and practice (4th ed.) (pp. 67-96). San Francisco, CA: Jossey-Bass.

National Heart, Lung, and Blood Institute. (2006). Your guide to lowering your blood pressure with DASH. https://www.nhlbi.nih.gov/files/docs/public/heart/new_dash.pdf

Reiss, S. (2004). Multifaceted nature of intrinsic motivation: The theory of 16 basic desires. Review of General Psychology, 8(3), 179-193. https://doi.org/10.1037/1089-2680.8.3.179

Ryan, P. (2009). Integrated theory of health behavior change: Background and intervention development. Clinical Nurse Specialists, 23(3), 161-170. https://doi.org/10.1097/NUR.0b013e3181a42373

Satter, E. (2007). Hierarchy of food needs. Journal of Nutrition Education and Behavior, 39(5), 187-188. https://doi.org/10.1016/j.jneb.2007.01.003

Skinner, B. F. (2014). Science and human behavior. http://www.bfskinner.org/newtestsite/wp-content/uploads/2014/02/ScienceHumanBehavior.pdf

Skinner, B. F. (2016). The technology of teaching. http://www.bfskinner.org/wp-content/uploads/2016/04/ToT.pdf

Yu, J. M. (2013). Introduction. In J. M. Yu (Eds.), Health behavior and health education. Shanghai: Fudan University Press. [In Chinese]

Zeevi, D., Korem, T., Zmora, N., Israeli, D., Rothschild, D., Weinberger, A., ... Segal, E. (2015). Personalized nutrition by prediction of glycemic responses. Cell, 163(5), 1079-1094. https://doi.org/10.1016/j.cell.2015.11.001

\section{Copyrights}

Copyright for this article is retained by the author(s), with first publication rights granted to the journal.

This is an open-access article distributed under the terms and conditions of the Creative Commons Attribution license (http://creativecommons.org/licenses/by/4.0/). 